\title{
The Effects of Interfacial Tensions of Amphiphilic Copolymers on Honeycomb-Patterned Films
}

\author{
By Miki KoJIma, ${ }^{1, *}$ Yuji HiRAI, ${ }^{1}$ Hiroshi YABU $^{2}$ and Masatsugu ShIMomura ${ }^{2,3,4}$
}

\begin{abstract}
A honeycomb-patterned film is formed by casting a polymer solution of polystyrene and amphiphilic copolymer under humid condition. Amphiphilic copolymers stabilize condensed water droplets as temporal templates. Therefore, physical properties of the amphiphilic copolymer are important factors for stability of condensed water droplets and the structure of the honeycomb-patterned film. In order to verify the effect of the interfacial tension between water and chloroform solution of the amphiphilic copolymer, which is one of the important physical properties, amphiphilic copolymers were synthesized from hydrophobic monomer and hydrophilic monomer at various copolymerization ratios. The interfacial tension decreased with increasing the copolymerization ratio of the hydrophilic comonomer. Uniformity of micropores of the honeycomb-patterned film increased with decreasing the value of the interfacial tension. Moreover, polymer frame of honeycomb-patterned film became thinner with decreasing the value of the interfacial tension. These results indicate that the structure of honeycombpatterned film can be controlled by the interfacial tension between water and polymer solution.

KEY WORDS: Honeycomb-Patterned Film / Self-Organization / Amphiphilic Copolymer / Interfacial Tension /
\end{abstract}

Honeycomb-patterned polymer films with uniform-sized pores ranging submicron to micron size can be obtained by casting polymer solution under humid condition. ${ }^{1-4}$ The pores are formed by using a temporal template of water droplet array condensed on the solution surface cooled by evaporation heat of the solvent. The pore size can be controlled by changing the preparation conditions (e.g., humidity of atmosphere, casting volume, etc) ${ }^{5}$ It has been reported that honeycomb-patterned films can be used as superhydrophobic materials, ${ }^{3,6}$ scaffolds for cell culturing, ${ }^{2,7-9}$ and so on. Furthermore, various micro structures such as pincushion structures, ${ }^{10}$ microsphere arrays ${ }^{11}$ and so on were fabricated based on secondary processing of the honeycomb-patterned films.

Wide variety of materials, including block copolymers, ${ }^{12-15}$ star polymers, ${ }^{16-18}$ dendrimers ${ }^{19}$ can be used to prepare the honeycomb-patterned films. Amphiphilic copolymers (polyacrylamide, ${ }^{20}$ polyion complex $^{21}$ ) are suitable polymers for preparation of the honeycomb-patterned films. Highly-ordered honeycomb-patterned films are also formed from conventional polymers such as polystyrene by the addition of amphiphilic copolymers to casting polymer solutions under humid condition. In general, amphiphilic compounds have physical properties of interfacial adsorption and stabilization. In the formation process of honeycomb-patterned film, amphiphilic copolymer acts as a stabilizer of the W/O (water in oil) emulsion and prevents fusion of water droplets.

It has been reported that amphiphilic copolymer is condensed on the edge of pores of the honeycomb-patterned film prepared from mixture of poly(bisphenol A carbonate) and amphiphilic copolymer. ${ }^{22}$ Moreover, fluorescence was ob- served at edge of pores of honeycomb-patterned film prepared from mixture of polystyrene and dye-containing amphiphilic copolymer. ${ }^{23}$ From these results, amphiphilic copolymer localizes at the interface of water droplets, which are the temporal template for honeycomb-patterned film formation.

Stability of water droplets depends on physical properties of amphiphilic copolymers, and their physical properties depend on their chemical structures, hydrophilic-hydrophobic balances, molecular weights, functional moieties, etc. Recently, we have found that the interfacial tension of the amphiphilic compounds is one of dominant physical properties of honeycomb pattern formation. ${ }^{24}$ In this report, hydrophobic $N$ dodecylacrylamide and hydrophilic 6-acrylamidohexanoic acid were polymerized at various copolymerization ratios, and amphiphilic copolymer, which are composed by same chemical species and have different hydrophilic-hydrophobic balance, were synthesized. Here, relationship among chemical structure of amphiphilic copolymer, their interfacial tension, and structure of honeycomb-patterned film is discussed.

\section{EXPERIMENTAL}

\section{Copolymerization of Amphiphilic Copolymer}

Monomers of the amphiphilic copolymer were synthesized according to the literture. ${ }^{20}$ Benzene, $N, N$-dimethylsulfoxide (DMSO), methanol, and 2,2'-azobisisobutyronitrile (AIBN) were purchased from Wako Pure Chemical Industries Ltd., Japan. AIBN, which is an initiator, was recrystallized in methanol. $\mathrm{N}$-dodecylacrylamide (M1), 6-acrylamidohxanoic acid (M2), and AIBN were dissolved in mixture of benzene

\footnotetext{
${ }^{1}$ Graduate School of Engineering, Tohoku University, 6-6, Aramaki Aza Aoba, Aoba-ku, Sendai 980-8579, Japan

${ }^{2}$ Institute of Multidisciplinary Research for Advanced Materials, Tohoku University, Katahira 2-1-1, Aoba-ku, Sendai 980-8577, Japan

${ }^{3}$ WPI Advanced Institute for Materials Research, Tohoku University, Katahira 2-1-1, Aoba-ku, Sendai 980-8577, Japan

${ }^{4}$ Core Research for Evolutional Science and Technology, Japan Science and Technology Agency, 3-4-15, Nihonbashi, Chuo-ku, Tokyo 103-0027, Japan

*To whom correspondence should be addressed (Tel: +81-22-217-5329, Fax: +81-22-217-5329, E-mail: kojima@mail.tagen.tohoku.ac.jp).
} 
Table I. Polymerization condition and characterization of amphiphilic polymers

\begin{tabular}{|c|c|c|c|c|c|c|c|c|}
\hline Polymer & $\begin{array}{c}\text { M1 } \\
{[\mathrm{mmol}]}\end{array}$ & $\begin{array}{c}\text { M2 } \\
{[\mathrm{mmol}]}\end{array}$ & $\begin{array}{c}\text { AlBN } \\
{[\mathrm{mmol}]}\end{array}$ & $\begin{array}{c}\text { Yield } \\
{[\%]}\end{array}$ & $M_{\mathrm{n}}$ & $M_{\mathrm{w}} / M_{\mathrm{n}}$ & M1:M2* & $\begin{array}{l}\text { Solubility in } \\
\text { chloroform }\end{array}$ \\
\hline P1 & 29.2 & 2.90 & 0.66 & 88.5 & $2.5 \times 10^{4}$ & 3.76 & 7.6:1.0 & soluble \\
\hline $\mathrm{P} 2$ & 29.6 & 7.30 & 0.74 & 87.0 & $3.7 \times 10^{4}$ & 3.50 & 4.0:1.0 & soluble \\
\hline P3 & 20.9 & 10.5 & 0.63 & 20.0 & $4.4 \times 10^{4}$ & 2.97 & $1.9: 1.0$ & soluble \\
\hline P4 & 18.0 & 18.0 & 0.66 & 26.4 & $1.0 \times 10^{5}$ & 2.44 & $0.9: 1.0$ & insoluble \\
\hline
\end{tabular}

*Copolymerization ratio of M1:M2 is estimated from $\mathrm{C} / \mathrm{N}$ from elemental analysis.

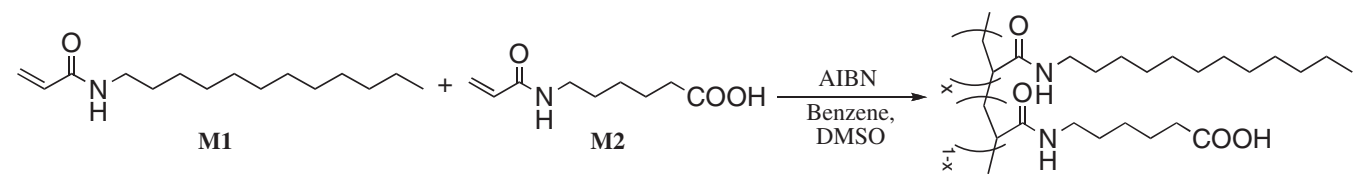

Scheme 1

(distilled, 70-80 mL) and DMSO (distilled, 2-4 mL) at the amount shown in Table I in a four neck flask, equipped with a nitrogen inlet, a thermometer, a reflux condenser and a septum. After three cycles of freeze-thaw-evacuate, free-radical polymerization was conducted at $60{ }^{\circ} \mathrm{C}$ for $6-10 \mathrm{~h}$ in oil bath under nitrogen atmosphere (Scheme 1). ${ }^{20}$ Reaction liquid was dropped into poor solvent ( $\mathrm{P} 1, \mathrm{P} 2, \mathrm{P} 3$ into acetonitrile and P4 into ethyl acetate and then hexane), to purify the synthesized polymers by reprecipitation. Polymers were collected by centrifugation and dried in vacuo. Chemical structures and copolymerization ratios of the polymers were determined by ${ }^{1}$ H NMR (LAMBDA 400, JEOL Ltd., Japan) and elemental analysis. ${ }^{25-28}$ Molecular weights of polymers were measured by size exclusion chromatography (SEC) using the Shodex K-804 (Showa Denko K.K., Japan) column at $50^{\circ} \mathrm{C}$ (polystyrene as standard). Chloroform (P1 and P2) or tetrahydrofuran (P3 and P4) were used as the carrier solvent, and its flow rate was $1.0 \mathrm{~mL} / \mathrm{min}$. Four types of amphiphilic polymers with different monomer ratio were obtained. $\mathrm{P} 1, \mathrm{P} 2$ and $\mathrm{P} 3$ were soluble in chloroform, however, $\mathrm{P} 4$ was not dissolved in chloroform.

\section{Preparation and Observation of Polymer Film}

Chloroform and polystyrene (average $M_{\mathrm{w}}$ 280,000) were purchased from Wako Pure Chemical Industries Ltd. (Japan) and Sigma-Aldrich (USA), respectively. Nine different chloroform solutions were prepared with changing the concentration and types of polymers. The polymer solution was cast on a glass dish $(\phi 9 \mathrm{~cm})$ in a box. Humidity and temperature were controlled (r.t., r.h. 20\%) and humid air (ca. 90\%) was applied on the solution surface at its flow rate of $4.0 \mathrm{~L} / \mathrm{min}$. After complete evaporation of solvent, a polymer film was obtained. The polymer films were coated with osmium (HPC-1SW, Vacuum Device Inc., Japan), their surface structures were observed by scanning electron microscope (SEM, TM-1000, Hitachi High-Technologies Corporation, Japan). Average pore size $(\phi)$ and standard deviations (SDs) were measured from binary-contrasted SEM images by using an imaging software $\left(\right.$ Image $\left.{ }^{29}\right)$. The tiny pores generated in the polymer frames were neglected. The smaller SD value means the higher uniformity of pore sizes.

\section{Measurements of Surface Temperature of Cast Polymer Solution}

Surface temperature of the cast solution was measured by using a thermography (TVS-700, Nippon Avionics Co., Ltd.). A chloroform solution of $5.0 \mathrm{mg} / \mathrm{mL}$ of polystyrene and 0.5 $\mathrm{mg} / \mathrm{mL}$ of $\mathrm{P} 2$ was prepared. The solution $(5 \mathrm{~mL})$ was cast on a Petri dish $(\phi 9 \mathrm{~cm})$ in the environment of $23.4{ }^{\circ} \mathrm{C}$ and r.h. $37 \%$ and humid air was applied at its velocity of $4 \mathrm{~L} / \mathrm{min}$ humid air. At the same time, the weight change of the solution was recorded by using an electronic balance.

\section{Measurements of Interfacial Tensions}

Interfacial tensions between water and chloroform solutions of amphiphilic copolymers (P1, P2 and P3) were measured by pendant drop method with an interfacial tension meter equipped with temperature controlling jacket (DM-300, Kyowa Interface Science Co., Ltd., Japan) at $5{ }^{\circ} \mathrm{C}$. Chloroform solutions of amphiphilic copolymers were prepared at their concentrations of $0.1,0.5,1.0 \mathrm{mg} / \mathrm{mL}$ at room temperature. Eight milliliter of the solution was poured in the quartz glass cuvette, and then a water drop was injected into the solution. The interfacial tensions were measured $500 \mathrm{~s}$ after water injection. The average interfacial tension values were calculated from ten measurement results.

\section{RESULTS AND DISCUSSION}

Figure 1 shows SEM images of the honeycomb-patterned films prepared from the nine chloroform solutions containing polystyrene and amphiphilic copolymers (P1, P2, and P3), respectively. $\mathrm{P} 4$ containing much hydrophilic moieties was not used in this experiment because it was not dissolved in chloroform. Three concentration of the amphiphilic copolymer was chosen $(0.1,0.5$ and $1.0 \mathrm{mg} / \mathrm{mL})$. The film prepared from the solution containing P1 polymer at the lowest concentration (solution S1) show a disordered texture with various sized pores. On the other hand, S2 and S3 gave microporous films with uniform-sized pores. The SD values of S2 and S3 (16\% and $14 \%$ ) were remarkably smaller than that of S1 (96\%). This means that the uniformity of the pore size is improved with 


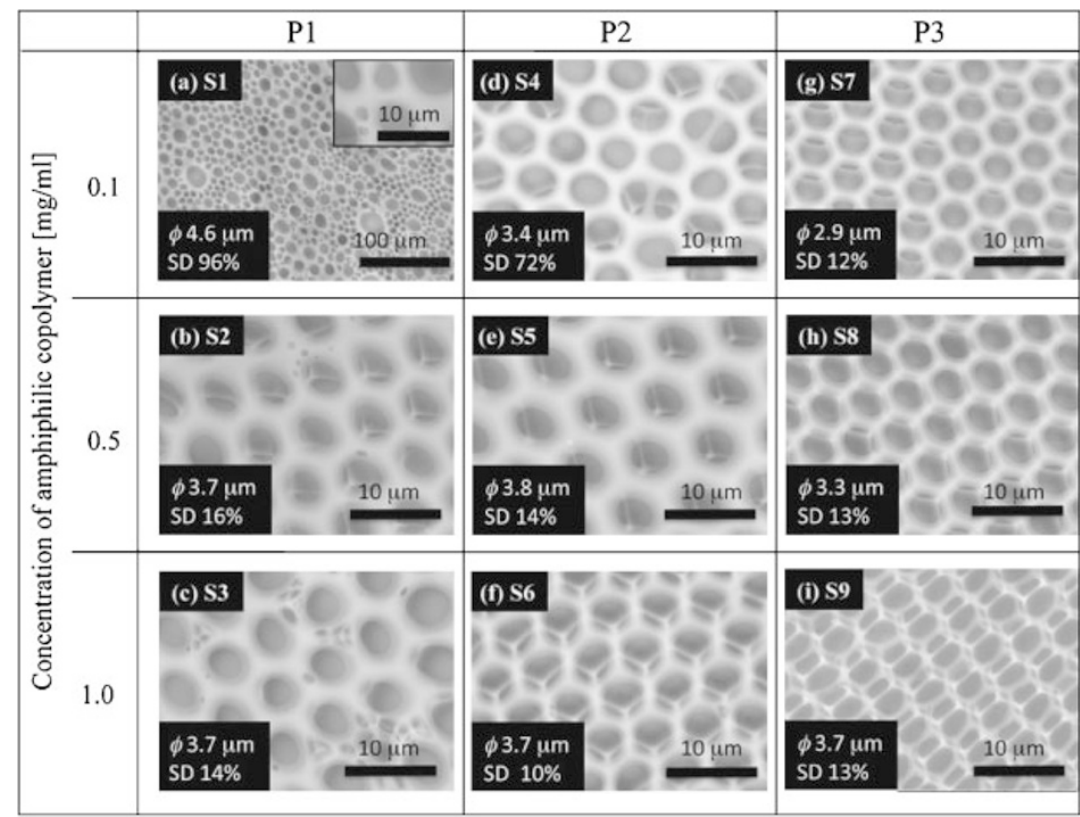

Figure 1. SEM images of polymer films prepared by casting solution of polystyrene and each amphiphilic copolymer (left column: P1, middle column: P2 and right column: P3).

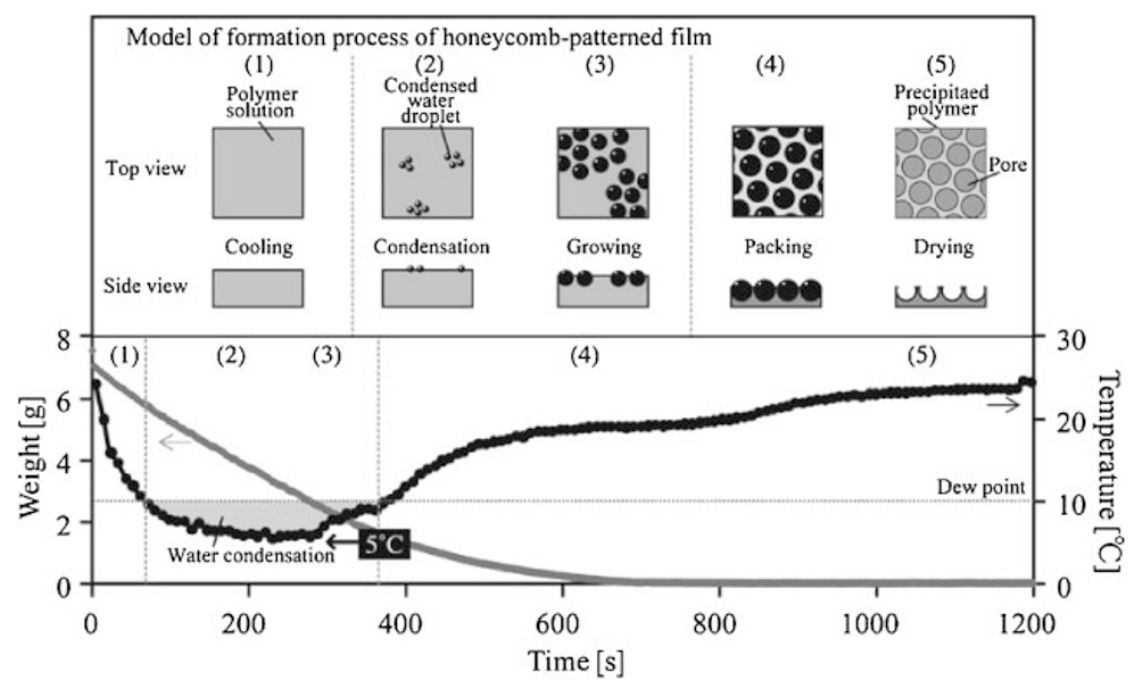

Figure 2. Weight change (gray line) and temperature change (black line) of the sample after casting polymer solution. The image above shows schematic illustration of formation process of honeycomb-patterned film.

increasing concentration of the amphiphilic copolymer. Similar concentration effect was observed in the P2 polymer solutions, $\mathrm{S} 4, \mathrm{~S} 5$ and S6. In the case of P3 polymer solutions (S7, S8 and S9), uniform-sized pores were formed even at the lowest amphiphilic copolymer concentration (S7). The SD values clearly decreased with increasing the copolymerization ratios of the hydrophilic comonomers $(96,72$, and $12 \%$ for S1, S4 and $\mathrm{S} 7$, respectively).

Concentration and composition of amphiphilic copolymers change interfacial tension between water and polymer solution. Generally, an interfacial tension is decreased with addition of surfactants. The interfacial tension is one of the representative values of the characters of surfactants. It is well known that the interfacial tensions also depend on the temperature. During the honeycomb-patterned film formation, the solution surface is cooled by evaporation heat. The change of surface temperature of the cast solution was measured to reveal the temperature during the formation process of honeycomb-patterned film. Figure 2 shows the changes of temperature and weight of casting solution and schematic illustration of solution surface. Weight of the solution reduced due to solvent evaporation. During the solvent evaporation, the surface temperature of the solution reached $c a .5^{\circ} \mathrm{C}$, and then elevated to room temperature gradually after complete evaporation of the solvent. In this environment, the dew point is $c a .10^{\circ} \mathrm{C}$, therefore water droplets condensed on the solution surface under $10^{\circ} \mathrm{C}$. 


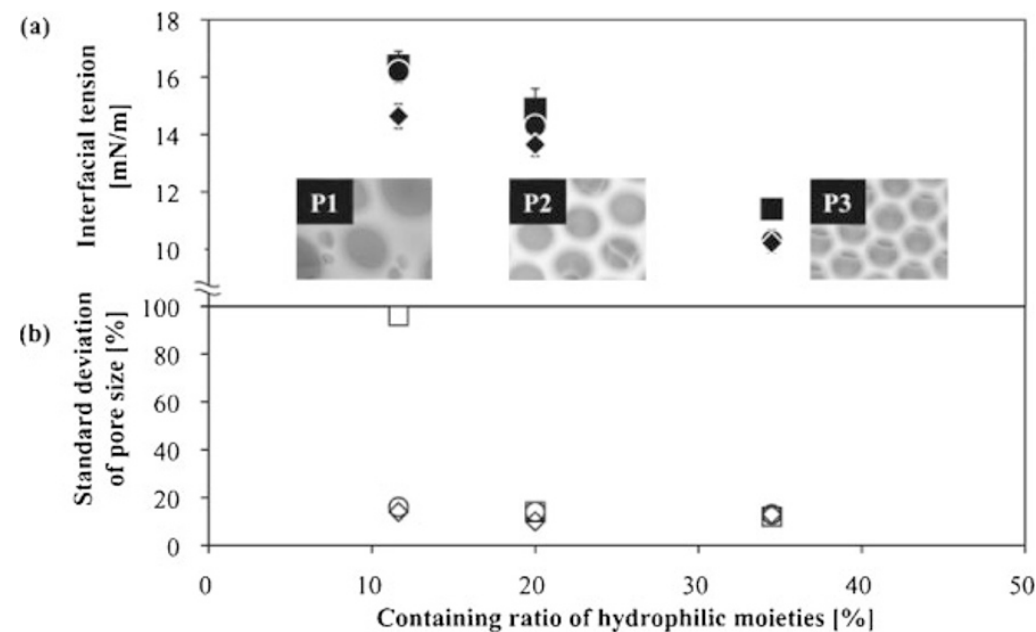

Figure 3. (a) Average interfacial tension between water and chloroform solution of amphiphilic copolymer at the concentration of $0.1(\square), 0.5(\bullet)$, and $1.0 \mathrm{mg} / \mathrm{mL}$ $(\diamond)$ at $5^{\circ} \mathrm{C}$. (b) SD of pore sizes of films prepared from chloroform solution of $1.5 \mathrm{mg} / \mathrm{mL}$ polystyrene and $0.1(\square), 0.5(\bigcirc), 1.0 \mathrm{mg} / \mathrm{mL}(\diamond) \mathrm{amphiphilic}$ copolymers for containing ratio of hydrophilic moieties.

Honeycomb-patterned film is obtained through the process as follows: (1) Solution surface is cooled by evaporation heat of the solvent. (2) The temperature of the solution is cooled under the dew point and water droplets are condensed on the solution surface. (3) Water droplets grow during the solvent evaporation. (4) Water droplets are packed by capillary force or convection of the solution. ${ }^{30}$ (5) Porous polymer film is obtained after evaporation of water droplets. From the results, $5^{\circ} \mathrm{C}$ is the lowest temperature in the process of water droplets condensation and growth. Thus, the interfacial tensions were measured at $5{ }^{\circ} \mathrm{C}$.

Average interfacial tensions between water and chloroform solutions of the amphiphilic polymers were shown in Figure 3a. The interfacial tensions decreased with increasing hydrophilic moieties in amphiphilic copolymers. The interfacial tensions also decreased with increasing the concentration of the amphiphilic copolymers. In Figure 3b, the SD values of pore sizes were shown. In the case of P2 and P3, the SD values were smaller than that of $\mathrm{P} 1$ at the each concentration. These results indicate that the SD values decreased with increasing hydrophilic moieties in amphiphilic copolymers.

Moreover, size of the polymer frame decreased with the increasing hydrophilic moieties (Figure 4). Size of the polymer frames was measured at thinnest part from the SEM images of the films prepared from the solutions at their concentrations of $1.0 \mathrm{mg} / \mathrm{mL}$ of the amphiphilic polymers (S3, S6, S9) (Figure 3).

The polymer frames became thinner with decreasing the interfacial tensions. There are two reasons for thinning the polymer frames; one is sinking of water droplets into the solution, the other is deformation of water droplets due to decreasing of the interfacial tension.

When the water droplets are considered as a Pickering emulsion, the contact angle between contact line and the solution surface are calculate as $c a .60^{\circ}$ in the case of $\mathrm{P} 1$ to balance the water droplet at the air-solution interface. On the

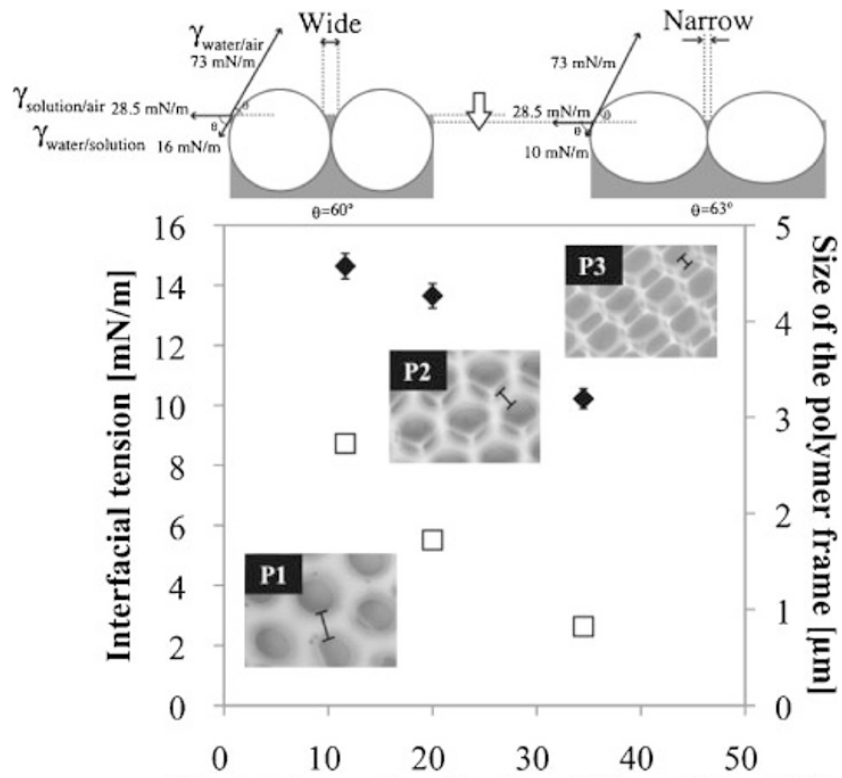

Containing ratio of hydrophilic moieties [\%]

Figure 4. Average interfacial tensions between water and chloroform solution of amphiphilic copolymer of $1.0 \mathrm{mg} / \mathrm{mL}(\Delta)$ at $5^{\circ} \mathrm{C}$ and size of the polymer frame $(\square)$ measured from SEM images for containing ratio of hydrophilic moieties.

other hand, the contact angle was $c a .63^{\circ}$ in the case of P3. The difference between the contact angles was only $3^{\circ}$. This difference was too small to change the thickness of the polymer frame. On the other hand, as shown in the literature ${ }^{31}$ (Govor et al.), shape of template water droplets is affected by interfacial tension at the three phase contact point. The interfacial tension between water and the solution decreased with increasing hydrophilic moieties of the amphiphilic copolymer. The interfacial tension decrease makes the water droplets from spherical to ellipsoidal to balance the Neuman triangle. This deformation induced the thinning of the frame. 
These results clearly indicate that the interfacial tension of amphiphilic copolymers is one of the important physical properties for determining the thickness of polymer frames.

\section{CONCLUSION}

Relation between uniformity of the microporous films and interfacial tensions between water and solutions of amphiphilic copolymers was discussed. When interfacial tension between water and chloroform solution was lower, the SD value of the pore sizes of the microporous film was smaller and the uniform microporous film was obtained. Moreover, polymer frame of honeycomb-patterned film was thinner with decreasing interfacial tension. It is indicated that the structure of honeycombpatterned film can be controlled by the characters of amphiphilic copolymers. From these results, various kinds of amphiphilic materials can be used for honeycomb-patterned film preparation when the interfacial tension between water and the solution are controlled.

Acknowledgment. The authors would like to thank Technical Services Section, Institute of Multidisciplinary Research for Advanced Materials, Tohoku University, for taking elemental analysis. This work was partly supposed by Grant-in-Aid for Scientific Research (A) (No. 18201019), Grant-in-Aid for Scientific Research for Priority Areas (No. 19022001) and Grant-in-Aid for JSPS fellows.

Received: February 5, 2009

Accepted: May 3, 2009

Published: June 24, 2009

\section{REFERENCES}

1. G. Widawski, M. Rawiso, and B. Francois, Nature, 369, 387 (1994).

2. T. Nishikawa, J. Nishida, R. Ookura, S. I. Nishimura, S. Wada, T. Karino, and M. Shimomura, Mater. Sci. Eng., C, 8-9, 495 (1999).

3. H. Yabu and M. Shimomura, Chem. Mater., 17, 5231 (2005).

4. U. H. F. Bunz, Adv. Mater., 18, 973 (2006).

5. T. Nishikawa, R. Ookura, J. Nishida, K. Arai, J. Hayashi, N. Kurono, T. Sawadaishi, M. Hara, and M. Shimomura, Langmuir, 18, 5734 (2002).

6. H. Yabu, Y. Hirai, M. Kojima, and M. Shimomura, J. Adhes. Sci. Technol., 22, 277 (2008).

7. S. Yamamoto, M. Tanaka, H. Sunami, E. Ito, S. Yamashita, Y. Morita, and M. Shimomura, Langmuir, 23, 8114 (2007).

8. Y. Fukuhira, E. Kitazono, T. Hayashi, H. Kaneko, M. Tanaka, M. Shimomura, and Y. Sumi, Biomaterials, 27, 1797 (2006).
9. D. Beattie, K. H. Wong, C. Williams, L. A. Poole-Warren, T. P. Davis, C. Barner-Kowollik, and M. H. Stenzel, Biomacromolecules, 7, 1072 (2006).

10. H. Yabu, M. Takebayashi, M. Tanaka, and M. Shimomura, Langmuir, 21, 3235 (2005).

11. H. Yabu and M. Shimomura, Langmuir, 21, 1709 (2005).

12. O. Pitois and B. Francois, Colloid Polym. Sci., 277, 574 (1999).

13. C. Y. Wang, Y. D. Mao, D. Y. Wang, Q. S. Qu, G. J. Yang, and X. Y. Hu, J. Mater. Chem., 18, 683 (2008).

14. K. H. Wong, T. P. Davis, C. Bamer-Kowollik, and M. H. Stenzel, Polymer, 48, 4950 (2007).

15. T. Hayakawa and S. Horiuchi, Angew. Chem., Int. Ed., 42, 2285 (2003).

16. A. S. Karikari, S. R. Williams, C. L. Heisey, A. M. Rawlett, and T. E. Long, Langmuir, 22, 9687 (2006).

17. L. A. Connal, R. Vestberg, P. A. Gurr, C. J. Hawker, and G. G. Qiao, Langmuir, 24, 556 (2008).

18. M. H. Stenzel-Rosenbaum, T. P. Davis, A. G. Fane, and V. Chen, Angew. Chem., Int. Ed., 40, 3428 (2001).

19. C. X. Cheng, Y. Tian, Y. Q. Shi, R. P. Tang, and F. Xi, Langmuir, 21, $6576(2005)$

20. J. Nishida, K. A. Nishikawa, S. Nishimura, S. Wada, T. Karino, T. Nishikawa, K. Ijiro, and M. Shimomura, Polym. J., 34, 166 (2002).

21. H. Yabu, M. Tanaka, K. Ijiro, and M. Shimomura, Langmuir, 19, 6297 (2003).

22. H. Yabu and M. Shimomura, Langmuir, 22, 4992 (2006).

23. M. Kojima, H. Yabu, and M. Shimomura, Macromol. Symp., 267, 4 (2008).

24. Y. Fukuhira, H. Yabu, K. Ijiro, and M. Shimomura, Soft Matter, 5, 2037 (2009).

25. ${ }^{1} \mathrm{H} 400-\mathrm{MHz} \mathrm{NMR}\left(\mathrm{CDCl}_{3}\right) \delta 3.31-2.91$ (b, $\left.1 \mathrm{H}, \mathrm{CONHCH}_{2}\right)$; 1.71-1.00 (b, 20H, $\mathrm{CH}_{2}$ ); 0.88 (t, 3H, $\mathrm{CH}_{3}$ ). Anal. Calcd. for $\left(\mathrm{C}_{15} \mathrm{H}_{29} \mathrm{NO}\right)_{\mathrm{m}}\left(\mathrm{C}_{9} \mathrm{H}_{15} \mathrm{NO}_{3}\right)_{\mathrm{n}}$ : C, 74.04; H, 11.91; N, 5.98. Found: $\mathrm{C}$ 72.59; H, 11.62; N, 5.92.

26. ${ }^{1} \mathrm{H} 400-\mathrm{MHz}$ NMR $\left(\mathrm{CDCl}_{3}\right) \delta 3.05-2.81$ (b, $\left.1 \mathrm{H}, \mathrm{CONHCH}_{2}\right)$, 1.73-0.92 (b, $\left.19 \mathrm{H}, \mathrm{CH}_{2}\right), 0.88$ (t, $\left.3 \mathrm{H}, \mathrm{CH}_{3}\right)$. Anal. Calcd. for $\left(\mathrm{C}_{15} \mathrm{H}_{29} \mathrm{NO}\right)_{\mathrm{m}}\left(\mathrm{C}_{9} \mathrm{H}_{15} \mathrm{NO}_{3}\right)_{\mathrm{n}}: \mathrm{C}, 72.51 ; \mathrm{H}, 11.55 ; \mathrm{N}, 6.12$. Found: $\mathrm{C}$, 70.98; H, 11.24; N, 6.00 .

27. ${ }^{1} \mathrm{H} 400-\mathrm{MHz} \mathrm{NMR}\left(\mathrm{CDCl}_{3}\right) \delta 3.39-2.82\left(\mathrm{~b}, 2 \mathrm{H}, \mathrm{CONHCH}_{2}\right), 1.72$ 1.36 (b, 1H, $\mathrm{CH}_{2}$ ), 1.33-0.90 (b, 19H, $\left.\mathrm{CH}_{2}\right), 0.88\left(\mathrm{t}, 3 \mathrm{H}, \mathrm{CH}_{3}\right)$. Anal. Calcd. for $\left(\mathrm{C}_{15} \mathrm{H}_{29} \mathrm{NO}\right)_{\mathrm{m}}\left(\mathrm{C}_{9} \mathrm{H}_{15} \mathrm{NO}_{3}\right)_{\mathrm{n}}$ : C, 70.54; H, 11.08; N, 6.33. Found: C, 68.59; H, 10.66; N, 6.20.

28. ${ }^{1} \mathrm{H} 400-\mathrm{MHz}$ NMR (Tetrahydrofuran-d8 and $N, N$-dimethylsulfoxide-d6) $\delta$ 3.37-2.91 (b, 4H, $\left.\mathrm{CONHCH}_{2}\right), 2.38-1.86(\mathrm{~b}, 4 \mathrm{H}$ $\mathrm{COCH}_{2}$ ), 1.71-1.06 (b, 30H, $\left.\mathrm{CH}_{2}\right), 1.00-0.78$ (b, 3H, $\mathrm{CH}_{3}$ ). Anal. Calcd. for $\left(\mathrm{C}_{15} \mathrm{H}_{29} \mathrm{NO}\right)_{\mathrm{m}}\left(\mathrm{C}_{9} \mathrm{H}_{15} \mathrm{NO}_{3}\right)_{\mathrm{n}}$ : C, 67.88; $\mathrm{H}, 10.45 ; \mathrm{N}, 6.60$. Found: C, 64.64; H, 9.73; N, 6.40 .

29. W. S. Rasband and U. S. ImageJ, National Institutes of Health, Bethesda, Maryland, USA, http://rsb.info.nih.gov/ij/, 1997-2008.

30. (a) N. D. Denkov, O. D. Velev, P. A. Kralchevesky, I. B. Ivanov, H. Yoshimura, and K. Nagayama, Langmuir, 8, 3183 (1992). (b) P. A. Kralchevsky and K. Nagayama, Langmuir, 10, 23 (1994).

31. L. V. Govor, I. A. Bashmakov, R. Kiebooms, V. Dyakonov, and J. Parisi, Adv. Mater., 13, 588 (2001). 